\title{
DOMÍNIOS HIDROGEOLÓGICOS NO MEIO FISSURAL DO LESTE DA ZONA DA MATA-MG E EXTREMO NOROESTE DO ESTADO DO RIO DE JANEIRO
}

\author{
José Augusto Costa Gonçalves ${ }^{1}$ \\ Paulo Cyro Baptista Scudino ${ }^{2}$ \\ Frederico Garcia Sobreira ${ }^{3}$
}

\begin{abstract}
RESUMO
Esse trabalho mostra a pesquisa hidrogeológica desenvolvida em terreno cristalino com manto de intemperismo, com objetivo de caracterizar os aqüíferos, usando como ferramenta um cadastro de 206 poços e suas respectivas análises físico-químicas. A grande variação litológica e um heterogêneo grau de fraturamento, aliados ao relativamente espesso manto de intemperismo, com cerca de 25 metros em média de espessura, caracterizam os aqüíferos da área. Esses aqüíferos, analisados quanto ao condicionamento estrutural, à vazão específica, à condutividade elétrica, mostraram-se diferenciados, resultando de forma preliminar, na subdivisão dos mesmos em Domínios Hidrogeológicos A e B. Para ambos os Domínios, verificaram-se valores médios de vazão específica de 0,1234 L/s/m e 0,2331 $\mathrm{L} / \mathrm{s} / \mathrm{m}$; para a condutividade elétrica os valores médios foram de $132,42 \mu \mathrm{s} / \mathrm{cm}$ e 276,42 $\mu \mathrm{s} / \mathrm{cm}$, respectivamente. Traços estruturais espaçados e difusos são característicos do Domínio Hidrogeológico A, enquanto uma densa linearidade de traços estrutural marca o Domínio Hidrogeológico B.
\end{abstract}

\begin{abstract}
This paper has shown the hydrogeological research developed in crystalline terrain with mantle of weathering in order to characterise the aquifers, estimate the volumes of the ground waters as also to classify them chemically, using like a tool one survey map of wells and their respective physico-chemical analyses. A large lithological variation and a heterogeneous grade of faulting, connected to the relatively dense mantle of weathering which measures about $25 \mathrm{~m}$ in average of thickness, have characterised the aquifers from the site. These aquifers have been analysed considering the structural conditioning, specifical discharge, electrical conductivity, and so they had shown themselves differentiated, which resulted in the subdivisions from both ones into Hydrogeological Domains A and B. To both, average values to specifical discharge had been verified: $0.1234 \mathrm{~L} / \mathrm{s} / \mathrm{m}$, and $0.2331 \mathrm{~L} / \mathrm{s} / \mathrm{m}$; toward the electrical conductivity, these values were $132.42 \mu \mathrm{s} / \mathrm{cm}$ and $276.42 \mu \mathrm{s} / \mathrm{cm}$, respectively. Structural and diffuse traces have been characterised in the Hydrogeological Domain A while a dense linearity of structural traces has marked the Hydrogeological Domain B.
\end{abstract}

Palavras-chaves - Água Subterrânea, Meio Fissural, Aqüífero.

\footnotetext{
${ }^{1}$ Doutorando pelo Departamento de Geologia-Universidade Federal de Ouro Preto-Morro do Cruzeiro-CEP: 35.400-000-Ouro Preto/MG - Tel. 313559 1605/Fax. 3135591606 - e-mail: costa@degeo.ufop.br

${ }^{2}$ Departamento de Geologia-Universidade Federal de Ouro Preto-Morro do Cruzeiro-CEP: 35.400-000-Ouro Preto/MG - Tel. 313559 1605/Fax. 3135591606 - e-mail: agua.bh@terra.com.br

${ }^{3}$ Departamento de Geologia-Universidade Federal de Ouro Preto-Morro do Cruzeiro-CEP: 35.400-000-Ouro Preto/MG - Tel. 313559 1605/Fax. 3135591606 - e-mail: sobreira@degeo.ufop.br
} 


\section{1 - Localização da área de estudo}

A área de estudo (Figura 1), localiza-se na Zona da Mata do Estado de Minas Gerais, abrangendo uma pequena faixa territorial do Noroeste do Estado do Rio de Janeiro, entre os paralelos $21^{\circ} 00^{\prime}$ e $21^{\circ} 24^{\prime}$ de latitude sul e os meridianos $42^{\circ} 05^{\prime}$ a $43^{\circ} 30^{\prime}$ de longitude oeste de Greenwich, perfazendo uma superfície na ordem de $6000 \mathrm{Km}^{2}$. Essa área tem cobertura cartográfica na folha Juiz de Fora (SF-23-X-D), na escala de 1:250.000.

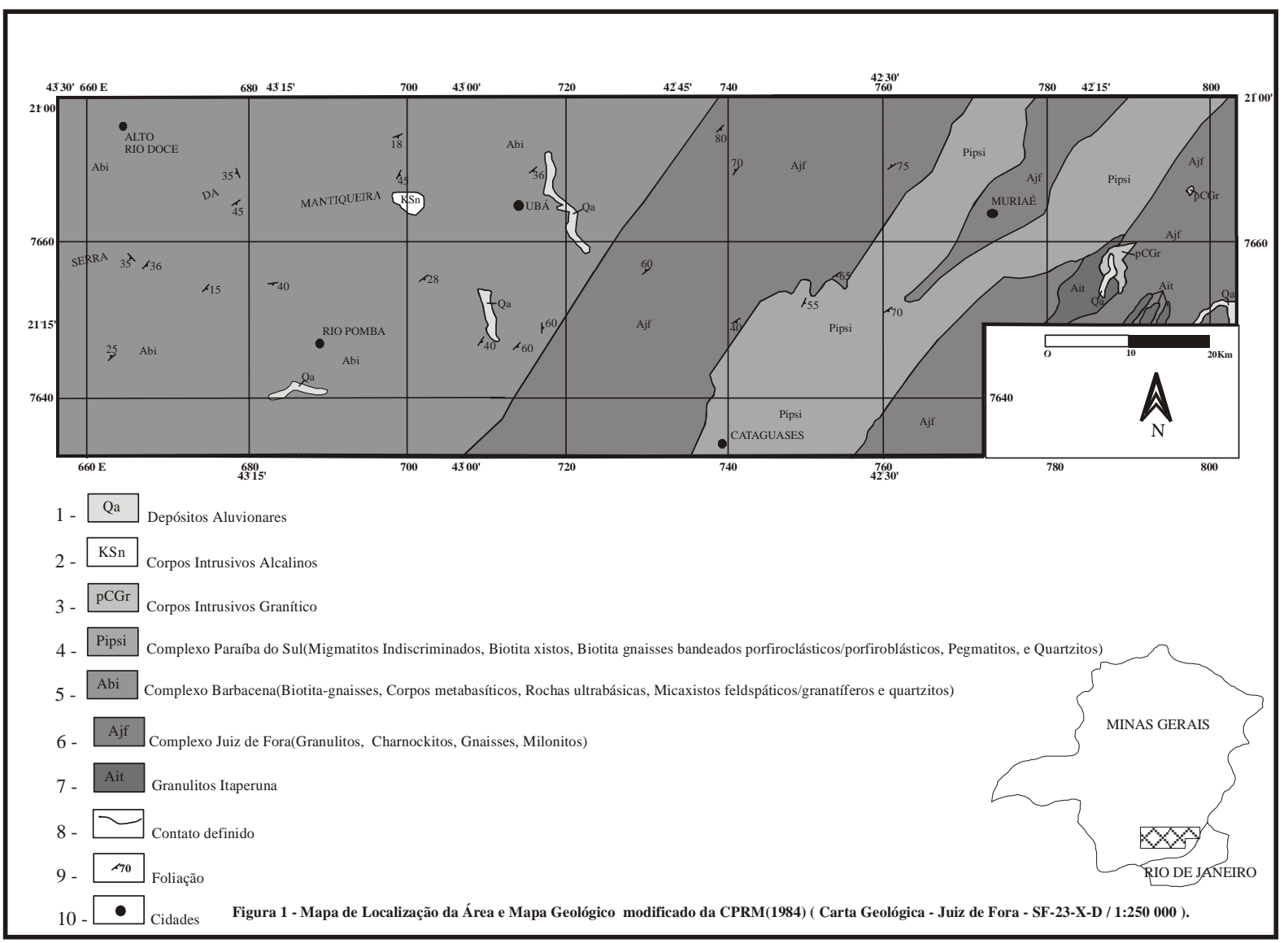

2 - Sistemas Aqüíferos: Identificação e características litológicas

A região está inserida hidrogeologicamente no Mapa de Províncias Hidrogeológicas do Brasil (Pessoa et al, 1980) na Sub-província Escudo Oriental 6-b. Ao se considerar o ambiente geológico da área de estudo, identificam-se duas categorias de sistemas aqüíferos: um meio granular, caracterizado por depósitos aluvionares, e um meio fissural, representado por rochas cristalinas de diversas unidades litológicas. Em relação ao aqüífero fissural adotou-se duas entidades espaciais de agrupamento, caracterizadas por um ou mais tipos predominantes e bem definidos de rocha reservatório, ambas associadas a uma unidade geológica regional específica. Por não se terem poços cadastrados no meio granular, a sua identificação e descrição serão restritas ao âmbito geológico. As relações entre os sistemas aqüíferos e as unidades geológicas associadas, como os tipos de rochas dominantes, constam na Tabela 1. 
Tabela 1 - Sistemas Aqüíferos da área de estudo.

\begin{tabular}{|c|c|}
\hline Sistemas Aqüíferos & $\begin{array}{c}\text { Litologia Predominante e Unidades } \\
\text { Geológicas }\end{array}$ \\
\hline \multicolumn{2}{|c|}{ Meio Granular } \\
\hline Aluvial & Areias de depósitos aluviais - Quaternário \\
\hline Coberturas Detríticas e Manto de Alteração & Areias, Siltes e Argilas - Terciáro-Quaternário \\
\hline \multicolumn{2}{|c|}{ Meio Fissural } \\
\hline $\begin{array}{l}\text { Rochas da Associação Xistos-Gnaisses- } \\
\text { Migmatitos } \\
\text { (Rochas metamórficas orientadas) } \\
\text { Domínio Hidrogeológico A }\end{array}$ & $\begin{array}{l}\text { Biotita-Xistos, Biotita Gnaisses, Micaxistos, } \\
\text { Migmatitos Indiscriminados do Complexo } \\
\text { Paraíba do Sul (Pipsi) e Micaxistos, Biotita } \\
\text { Gnaisses do Complexo Barbacena (Abi) }\end{array}$ \\
\hline $\begin{array}{l}\text { Rochas da Associação Charnockito- } \\
\text { Granulito-Gnaisses-Granitos. } \\
\text { (Rochas metamórficas não orientadas) } \\
\text { Domínio Hidrogeológico B }\end{array}$ & $\begin{array}{l}\text { Charnockitos, Granulitos, Milonitos do } \\
\text { Complexo Juiz de Fora (Ajf), Granulitos } \\
\text { Itaperuna(Ait) e Intrusões Graníticas (pcGr) }\end{array}$ \\
\hline
\end{tabular}

\section{3 - Sistemas Aqüíferos: Descrições e Caracterizações}

$\mathrm{Na}$ área estudada, predominantemente constituída de rochas cristalinas de baixa permeabilidade primária, existem dois aqüíferos de comportamentos bastante distintos: um mais superficial, formado na maioria das vezes pelo regolito intemperizado e/ou depósitos quaternários de comportamento de meio granular e um mais profundo, formado por fraturas de rocha sã. O primeiro é regional e extenso, dando contornos à superfície do relevo. O segundo, subjacente, em geral, apresenta maior condutividade hidráulica e pode atingir grandes profundidades.

\section{1 - Meio Granular}

\subsection{1 - Aqüíferos em sedimentos aluviais}

Esses depósitos, que podem atingir até 15 metros de espessura, são encontrados ao longo da rede de drenagem, nos canais fluviais, nas planícies de inundação e nos terraços de acordo com Brandalise (1976). Contudo, por limitações de escala, apenas manchas de maior expressão foram representadas.

\subsection{2 - Aqüíferos em Coberturas Detríticas e Mantos de Alteração}

Esse sistema constitui os aqüíferos superficiais associados ao manto de alteração das rochas (saprólitos, elúvios e colúvios) e aos depósitos detríticos de cobertura do Terciário-Quaternário. Os mantos de alteração das rochas não estão representados no mapa de sistemas aqüíferos por limitação de escala do mapeamento, entretanto, ocorrem de modo generalizado se constituindo numa importante fonte de recarga das rochas fraturadas subjacentes, pois atua como um meio de captação da água precipitada em toda a superfície permeável (ou semipermeável), diminuindo a perda por escoamento e minimizando o processo de evaporação. Sua mineralogia e espessura são muito variáveis e guardam íntima relação com a litologia de origem e as condições climáticas atuantes.

\section{2 - Meio Fissural}

Para o meio fissural, as informações reunidas e tratadas regionalmente vieram indicar que os fatores mais determinantes e que influenciam quantitativa e qualitativamente nas águas subterrâneas dos domínios hidrogeológicos são o condicionamento estrutural e litológico derivados. A análise integrada destas informações sugerem em caráter preliminar, a compartimentação em dois domínios hidrogeológicos com características diferenciadas (Gonçalves, 2001).

O meio aqüífero fissural é caracterizado pela ausência ou presença muito reduzida de espaços vazios na rocha. Nesse aqüífero, a água se encontra em espaços representados por fissuras ou fraturas, juntas ou ainda em falhas, ocorrendo ainda em situações esporádicas, em vesículas.

Segundo Costa (1983), os principais fatores atuantes considerados no estudo de caracterização do meio fissural e que controlam os mecanismos de infiltração, percolação, armazenamento d'água e qualidade são: clima, relevo, hidrografia, 
coberturas (sedimentares, detríticas, manto de alteração), constituição litológica e estruturas. Sendo assim, para toda a área estudada, entende-se que, através de uma ótica regionalizada, com exceção dos condicionantes estruturais associados às litologias, todos os outros fatores atuaram de forma geralmente constante, influenciando de maneira homogênea o meio aqüífero fissural.

\subsection{1 - Domínios Hidrogeológicos do meio fissural}

Apesar de não terem sido alvos e objetivos principais desse trabalho, os lineamentos estruturais da área de estudo foram abordados a partir da análise de estruturas em escala macroscópica, num contexto regional, e através de trabalhos de detalhe onde os mesmos sugerem a existência de duas zonas de características distintas, denominadas de Domínios Hidrogeológicos $A$ e B. Tais considerações foram fundamentadas e verificadas utilizando-se como parâmetro hidráulico a vazão específica $(\mathrm{L} / \mathrm{s} / \mathrm{m})$ e como parâmetro físicoquímico a condutividade elétrica $(\mu \mathrm{s} / \mathrm{cm})$. Para que essas considerações tivessem consistência, certificou-se em campo de que todos os poços cadastrados se encontram locados em condições similares para fins de uma análise detalhada. Assim independentemente do tipo de rocha, na melhor situação morfológica, ou seja, em depressões geralmente de bacias hidrográficas, sendo evitados os poços localizados em topos de elevações, divisores hidrográficos, flancos de colinas ou vertentes dos vales.

\subsection{2 - Diferenciação quantitativa e qualitativa dos domínios hidrogeológicos}

Considerando a vazão específica o parâmetro que melhor reflete as características hidráulicas dos aqüíferos, verifica-se para os 114 poços cadastrados do Domínio Hidrogeológico A um valor médio de $0,1234 \mathrm{~L} / \mathrm{s} / \mathrm{m}$, enquanto para os 92 poços do Domínio Hidrogeológico B, encontrou-se um valor médio de 0,2331 $\mathrm{L} / \mathrm{s} / \mathrm{m}$. Utilizando-se da relação entre a freqüência das vazões específicas com o número de poços correspondentes para cada domínio hidrogeológico, verifica-se que os aqüíferos do Domínio Hidrogeológico B apresentam as maiores vazões específicas, conforme a Tabela 2.

Tabela 2 - Freqüência da Vazão Específica dos Poços em relação aos domínios hidrogeológicos.

\begin{tabular}{|c|c|c|c|c|}
\hline \multicolumn{5}{|c|}{ Freqüência (\%) da Vazão Específica dos Poços (L/s/m) } \\
(No Total de Poços para cada intervalo de vazão específica estabelecido)
\end{tabular}

Os resultados das análises consideradas em conjunto mostram que $77 \%$ das águas amostradas apresentam condutividade elétrica inferior a $200 \mu \mathrm{s} / \mathrm{cm}$, ao passo que apenas $2,82 \%$ mostra valores superior a 500 $\mu \mathrm{s} / \mathrm{cm}$. O valor médio da condutividade é de $189,22 \mu \mathrm{s} / \mathrm{cm}$, tendo um mínimo de 58,20 $\mu \mathrm{s} / \mathrm{cm}$ e um máximo de $1750,00 \mu \mathrm{s} / \mathrm{cm}$. Analisando os valores da condutividade elétrica das águas distintamente para os domínios hidrogeológicos, certificou-se da diferenciação dos mesmos de acordo com a maior ou menor quantidade de sais dissolvidos, conforme Tabela 3. 
Tabela 3 - Freqüência da condutividade elétrica das águas subterrâneas com relação aos domínios hidrogeológicos.

\begin{tabular}{|c|c|c|c|}
\hline \multicolumn{4}{|c|}{$\begin{array}{c}\text { Freqüência (\%) da Condutividade Elétrica ( } \mu \mathbf{s} / \mathbf{c m}) \\
\left(\mathrm{N} .^{\circ} \text { de Total de Análises para cada intervalo estabelecido) }\right.\end{array}$} \\
\hline & $<100$ & $100-200$ & $>200$ \\
$(13)$ & $(42)$ & $(16)$ \\
\hline $\begin{array}{c}\text { Domínio Hidrogeológico } \\
\text { A }\end{array}$ & $84,62 \%$ & $64,29 \%$ & $31,25 \%$ \\
\hline $\begin{array}{c}\text { Domínio Hidrogeológico } \\
\text { B }\end{array}$ & $15,38 \%$ & $35,71 \%$ & $68,75 \%$ \\
\hline
\end{tabular}

\subsection{3 - Descrição dos Domínios Hidrogeológicos}

\subsubsection{1 - Domínio Hidrogeológico A}

Esse domínio ocupa toda a região centro ocidental da área, representado geologicamente por rochas da Associação Xistos-Gnaisses-Migmatitos dos Complexos Paraíba do Sul e Barbacena respectivamente (Tabela 1, Figura 10), de direção NE-SW e pela Intrusão Alcalina de Ubari. Cobre assim, uma área de $3.943 \mathrm{~km}^{2}$, perfazendo $65,66 \%$ do total da região de estudo.

As rochas do Complexo Barbacena, de idade arqueana, são constituídas principalmente por micaxistos, anfibolitos, anfibólio xistos, gnaisses xistosos, metaultrabásicas serpentinizadas e tremolitizadas, talco-tremolita-xistos e tremolita xistos; o Complexo Paraíba do Sul, de idade proterozóica, é constituído principalmente por migmatitos indiscriminados, biotita-xistos, biotita gnaisses bandeados porfiroclásticos/porfiroblásticos, pegmatitos e quatzitos; o Complexo Juiz de Fora é formado por charnoquitos, granulitos, gnaisses e milonitos; e por último, pela rocha intrusiva alcalina de Ubari.

Os traços estruturais se caracterizam por serem espaçados e difusos, tendo as principais direções de falhamentos paralelos à direção geral de foliação NNE-SSW.

Os aqüíferos desse domínio são fraturados, locais, descontínuos, livres e semiconfinados, restritos a juntas e fraturas, recobertos pela presença de coberturas indiferenciadas e aluviões, associados a linhas de drenagem superficial, planícies de inundação e terraços. As chuvas e o elevado potencial de armazenamento, decorrentes dos relativamente espessos horizontes das coberturas aluvionares e rochas intemperizadas, são os principais contribuintes para a recarga dessa unidade aqüífera, restituindo também um significativo volume de água aos rios, através das inúmeras nascentes existentes por toda área.

$\mathrm{Na}$ Figura 2, um histograma de freqüência mostra que, dos 114 poços cadastrados nesse domínio, analisados quanto à espessura das coberturas de alteração e aluviões, apresentam um valor máximo de 60 metros, um mínimo de 4 metros e o médio de 25,26 metros. Espessuras superiores a 20 metros representam $65,78 \%$ do total de poços analisados, comprovando uma significativa condição para armazenamento de água.

Para uma análise das vazões específicas dos poços desse domínio hidrogeológico, o histograma (Figura 3), mostra que dos 114 poços amostrados, $57,89 \%$ representam valores até 0,1000 $\mathrm{L} / \mathrm{s} / \mathrm{m}$, indicando também um valor médio de $0,1234 \mathrm{~L} / \mathrm{s} / \mathrm{m}$, como uma amplitude entre 0 mínimo de $0,0048 \mathrm{~L} / \mathrm{s} / \mathrm{m}$ e o máximo de $0,5180 \mathrm{~L} / \mathrm{s} / \mathrm{m}$.

A distribuição das profundidades dos 114 poços computados (Figura 4), indica que $51,75 \%$ destes têm profundidades entre 50 a 90 metros. O valor máximo de profundidade é de 140 metros e o mínimo de 50 metros, tendo ainda um valor médio de 86,20 metros.

Para análise da profundidade útil dos poços desse domínio hidrogeológico, o gráfico (Figura 5), demonstra que 48,24\% dos poços estudados têm profundidade útil no intervalo entre 40 a 80 metros. O valor máximo é de 139,5 metros e o valor mínimo de 40,3 metros, com valor médio de 81,69 metros, para um total de 114 poços amostrados. 


\subsubsection{2 - Domínio Hidrogeológico B} Esse domínio ocupa uma larga faixa no centro da área de estudo, com direção NESW, e a porção extremo leste representada geologicamente por rochas da Associação Charnockito- Granulito- Gnaisses- Granitos

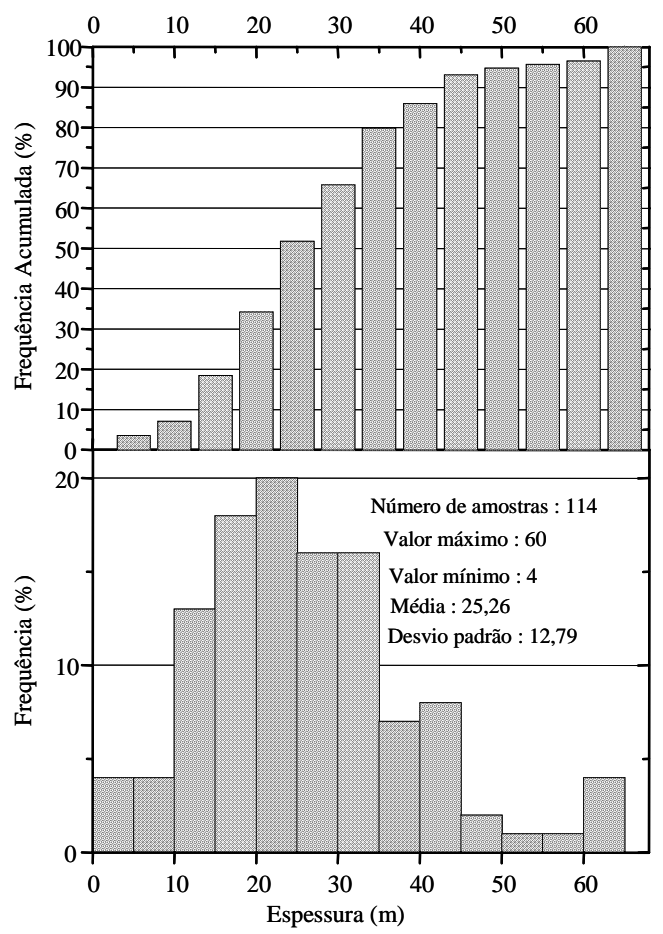

Figura 2 - Distribuição das espessuras dos mantos de alteração do Domínio Hidrogeológico A

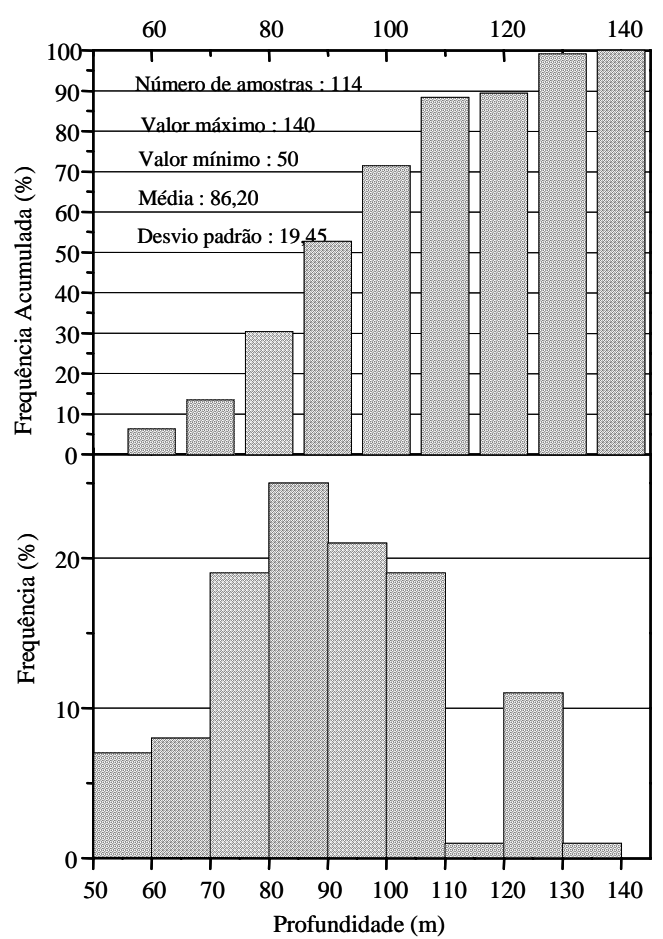

Figura 4 - Distribuição das profundidades dos poços do Domínio Hidrogeológico A

As rochas que constituem esse domínio são de idade arqueana e
Diversos do Complexo Juiz de Fora e Rochas Intrusivas Graníticas (Tabela 1, Figura 10), e cobre uma região de 2.023,5 $\mathrm{km}^{2}$, perfazendo $33,69 \%$ do total da área pesquisada.
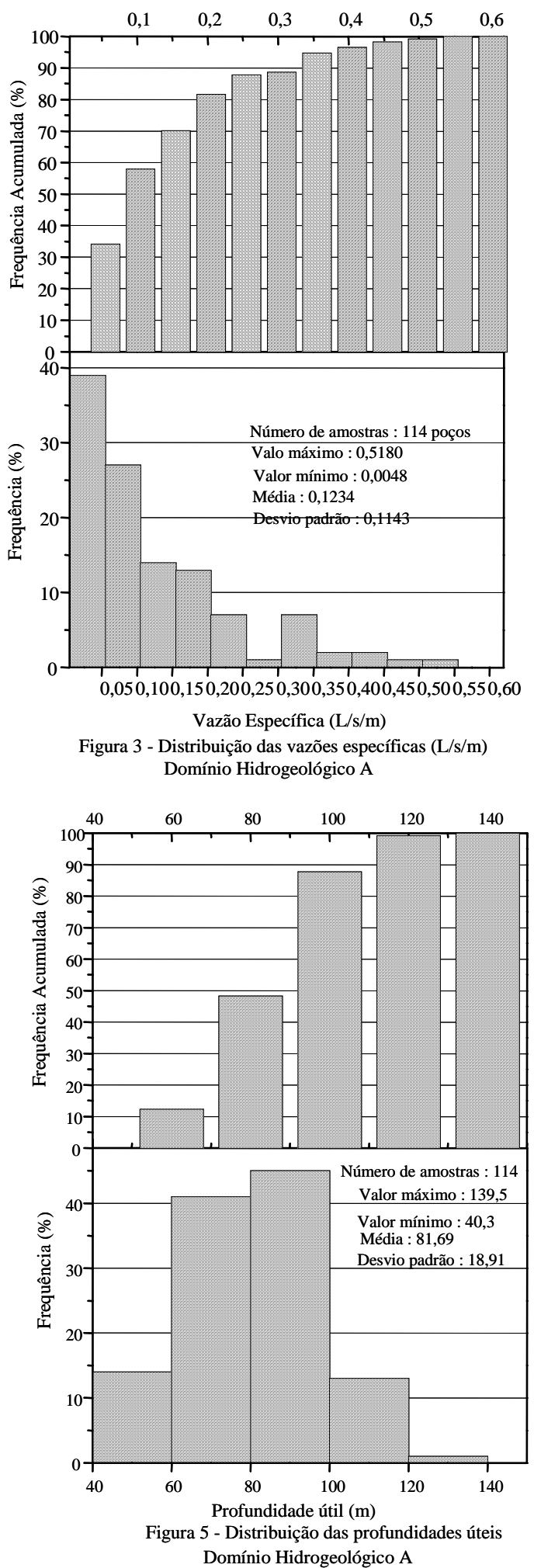

proterozóica, representadas por granulitos, gnaisses kinzigíticos, charnockitos, gnaisses 
e milonitos do Complexo Juiz de Fora e granitos intrusivos.

$\mathrm{Na}$ estruturação tectônica, esse domínio apresenta uma densa linearidade de traços estruturais, com as principais direções de falhamentos paralelas à direção geral de foliação NNE-SSW, com um estilo estrutural longitudinal e mergulhando para SE, evidenciando uma tectônica compressiva. Essa área é considerada como parte de um Bloco de Zonas de Cisalhamento (Fonseca, 1998).

Nesse domínio, os aqüíferos são fraturados, locais, descontínuos, livres e semiconfinados, restritos a juntas e fraturas, sendo recobertos pela ocorrência de aluviões e coberturas indiferenciadas, os quais não foram representados na Figura 10, por limitações de escala. Uma densa malha de fraturas, associada às coberturas de alteração e aluviais, constitui um sistema aqüífero livre onde a topografia passa a ser o principal fator responsável pela circulação das águas. A recarga da unidade aqüífera tem na rede de drenagem superficial e nas chuvas, os maiores contribuintes, sendo mais eficiente nas áreas onde o controle estrutural da drenagem se dá através das fraturas, que permitem uma contínua realimentação por meio dos aluviões, principalmente durante 0 período das chuvas.

A distribuição das espessuras das coberturas de alteração e aluviões (Figura $6)$, para um total de 92 poços amostrados, mostra que $50 \%$ desses apresentam valores acima de 20 metros. Verifica-se também um valor máximo de 51 metros, um valor mínimo de 4 metros e o valor médio de 21,42 metros.
Para analisar as vazões específicas desse domínio hidrogeológico, um histograma de freqüência (Figura 7), mostra que $53,26 \%$ dos 92 poços amostrados representam valores até $0,1000 \mathrm{~L} / \mathrm{s} / \mathrm{m}$, indicando um valor médio de $0,2331 \mathrm{~L} / \mathrm{s} / \mathrm{m}$, como uma variação entre o mínimo de $0,0003 \mathrm{~L} / \mathrm{s} / \mathrm{m}$ e o máximo de $2,6881 \mathrm{~L} / \mathrm{s} / \mathrm{m}$.

A distribuição das profundidades dos 92 poços computados (Figura 8), indica que $70 \%$ têm profundidades entre 50 a 90 metros. O valor máximo de profundidade para os poços dessa unidade aqüífera é de 156 metros e o mínimo de 50 metros, sendo o valor médio de 76,27 metros. Com relação à profundidade útil dos 92 poços estudados (Figura 9), 75\% desses representam poços de profundidade útil compreendidos no intervalo entre 40 a 80 metros, mostrando também um valor máximo de 147,2 metros, um valor mínimo de 28,1 metros e o valor médio de 70,95 metros.

\subsection{4 - Caracterização dos Domínios Hidrogeológicos}

\subsubsection{1 - Domínio Hidrogeológico A}

Esse domínio se apresenta menos fraturado que o domínio $B$, mostrando traços estruturais difusos e espaçados, cujas rochas, em sua grande maioria, possuem um caráter estrutural incompetente, ou seja, de comportamento geomecânico dúctil, devido à constituição litológica, representada principalmente por micaxistos, migmatitos e gnaisses xistosos. Além disso, por serem rochas ricas em minerais máficos e feldspatos, mais susceptíveis ao intemperismo químico, sofrem dissolução e precipitação de material argiloso nas fraturas, podendo reduzir a permeabilidade do meio. 
Rev. Águas Subterrâneas nํ17/ Maio 2003.

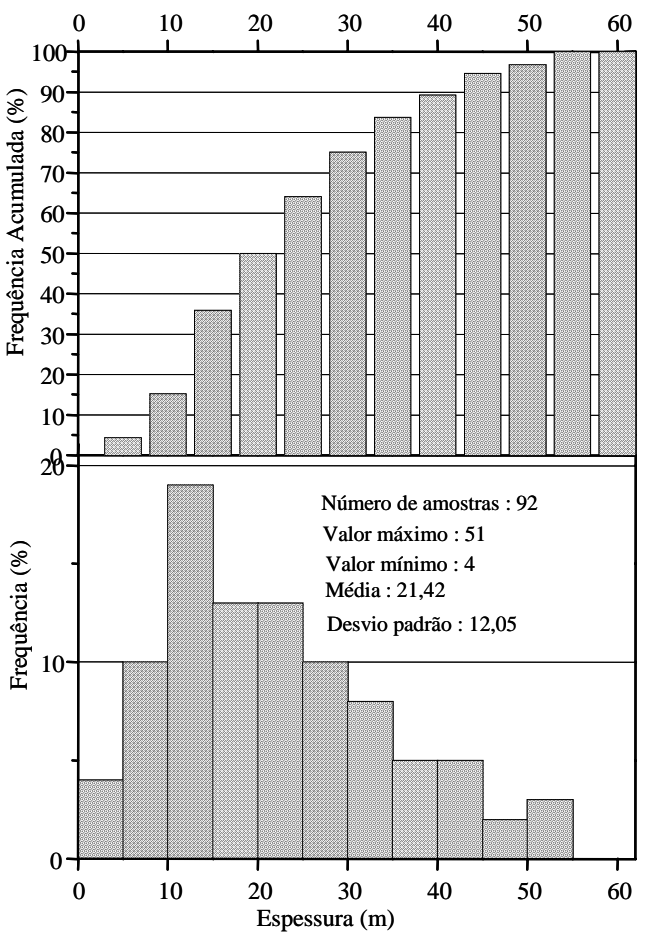

Figura 6 - Distribuição das espessuras dos mantos de alteração do Domínio Hidrogeológico B

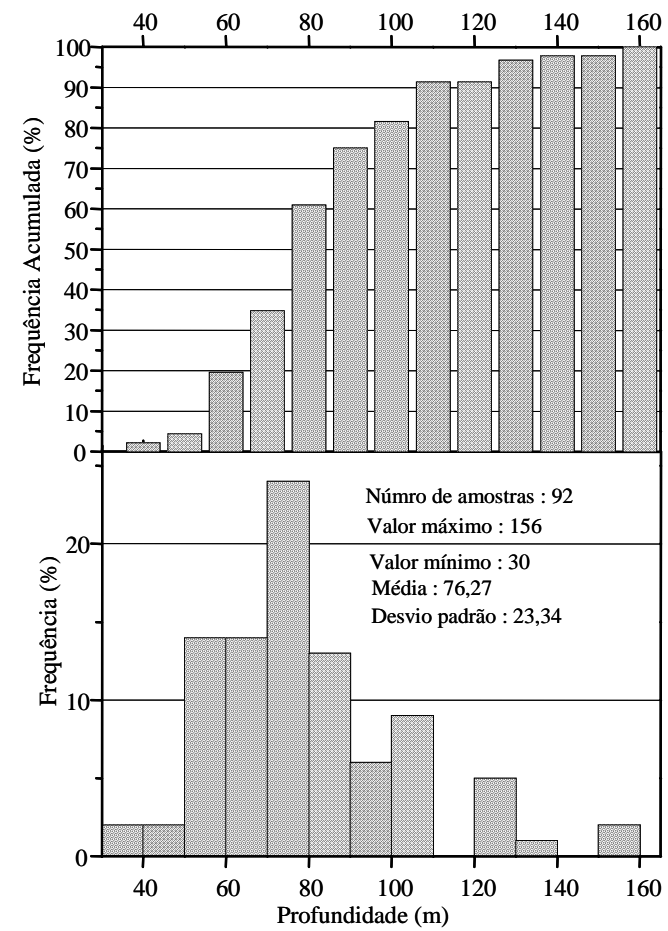

Figura 8 - Distribuição das profundidades dos poços do Domínio Hidrogeológico B

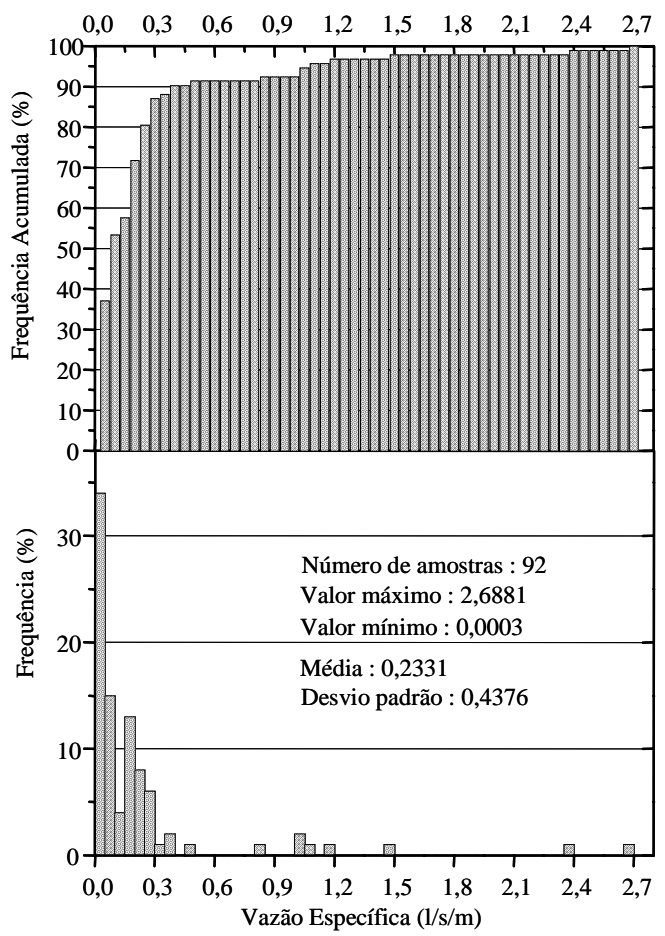

Figura 7 - Distribuição das vazões específicas do Domínio Hidrogeológico B

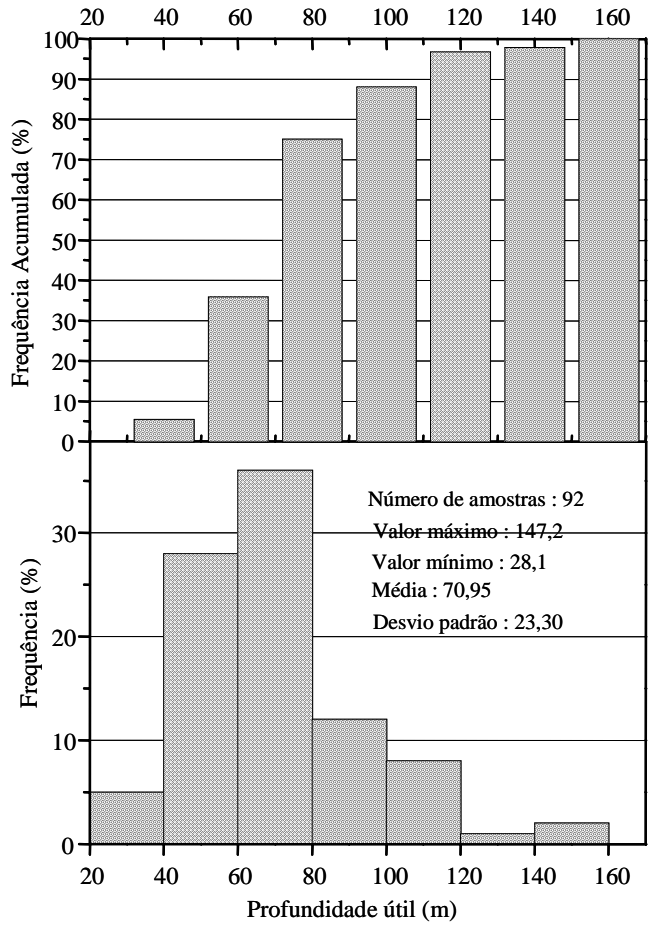

Figura 9 - Distribuição das profundidades úteis Domínio Hidrogeológico B 

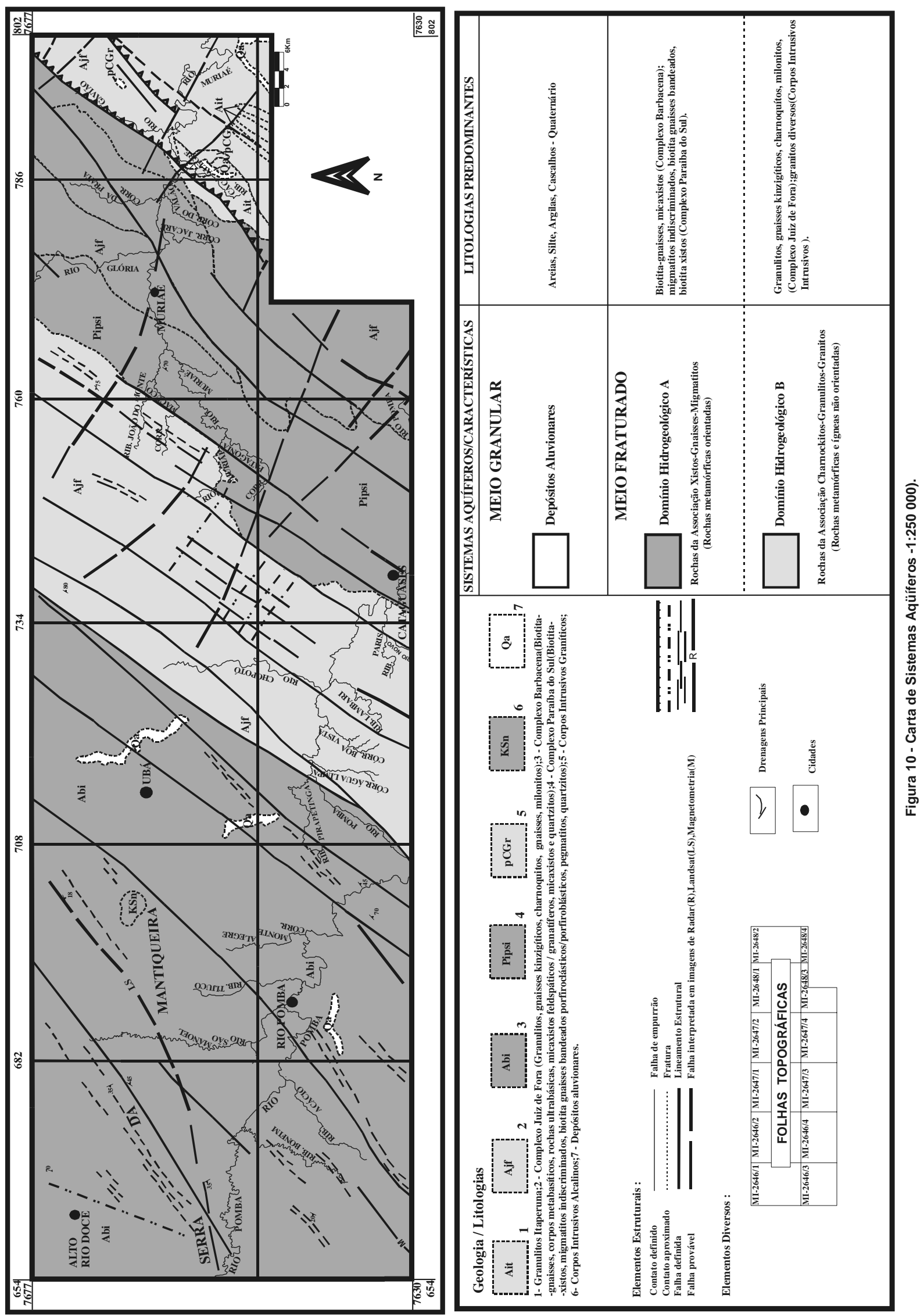
Outra resposta ao menor grau de fraturamento desse domínio é verificada no baixo teor de sais dissolvidos nas águas analisadas dessa porção, comprovado pelo valor médio da condutividade elétrica $(132,42 \mu \sigma / \mathrm{cm})$. Esse fato é justificável pelo menor caminho percorrido, menor tempo de circulação, proporcionando redução nos mecanismos de dissolução de minerais e maior renovação das águas nas zonas mais superiores.

\subsubsection{2 - Domínio Hidrogeológico B}

O domínio hidrogeológico B mostra maior densidade de traços estruturais, tanto na faixa central da área de estudo, como também na porção extremo leste, que é considerada parte de Bloco de Zonas de Cisalhamento, segundo Fonseca (1998). Esses fatores, associados à presença de rochas, representadas principalmente por granulitos, charnockitos e granitos diversos, em sua maioria de caráter estrutural rúptil, com menos plasticidade, produziram falhas abertas com menor espaçamento, favorecendo a existência de poços de boa produtividade.

Com a condutividade elétrica apresentando um valor médio de 276,42 $\mu \sigma / \mathrm{cm}$, as águas subterrâneas desse domínio mostram-se bem mais salinizadas quando comparadas com as do domínio hidrogeológico $A$, devido a uma maior $e$ mais profunda trama de caminhos, que favorecem as condições para dissolução de sais minerais.

\section{4 - Conclusões}

Apesar da inexistência de distinções climáticas, da grande semelhança dos litossomas e relativa similaridade na geomorfologia, verifica-se a existência de áreas mais favoráveis e promissoras para locação e perfuração de poços tubulares, apresentando as seguintes características: depressões topográficas abertas (evitar topos e flancos de colinas, como também divisores hidrográficos), associadas às zonas de fraturamento e/ou drenagem superficial, com coberturas detríticas ou manto de alteração.Verifica-se que aspectos hidrogeológicos e físico-químicos proporcionaram aos aqüíferos fissurais características diferenciadas, tanto quantitativa como qualitativamente. Esse fato possibilita a sugestão em caráter preliminar para os aqüíferos fissurais da área, a subdivisão em dois domínios hidrogeológicos, A e B.

\section{5 - Referências Bibliográficas}

Costa, W. D. 1983. Hidrogeologia de Terrenos Cristalinos. Apostila do Curso de Hidrogeologia. CPRM, Recife. p. 35-37.

Fonseca, M.J.G. et al. 1998. Mapa Geológico do Estado do Rio de Janeiro. Escala 1:400.000. DNPM, Rio de Janeiro, $141 \mathrm{p}$.

Brandalise, L. A . 1976. Projeto Vale do Paraíba. Relatório Final. Belo Horizonte. CPRM. 441 p.

Gonçalves, J.A.C. 2001. Contribuição à Hidrogeologia e à Hidroquímica do Leste da Zona da Mata de Minas Gerais e Extremo Noroeste do Estado do Rio de Janeiro. Departamento de Geologia, Universidade Federal de Ouro Preto, Ouro Preto, Dissertação de Mestrado, 102p.

Pessoa, M.D.; Mente, A.; Leal, O. 1980. Províncias Hidrogeológicas do Brasil. In: Congresso Brasileiro de Águas Subterrâneas, 1, Recife, Anais. p. 461-474. 